\title{
IMPLEMENTAÇÃO DE POLÍTICAS PÚBLICAS NA PESCA ARTESANAL: A ATUAÇÃO DOS BUROCRATAS DE NÍVEL DE RUA
}

\author{
Ivone Teresinha Angst ${ }^{1}$ \\ Fabio Kessler Dal Soglio²
}

\section{RESUMO}

Este artigo tem por objetivo analisar a atuação dos burocratas de nível de rua na construção e implementação das políticas públicas na pesca artesanal no município de Tramandaí/RS. Estes burocratas, denominados de implementadores, mediam a relação entre os cidadãos e o Estado, podendo influenciar a execução das políticas públicas. Objetivou-se, assim, compreender como estes implementadores influenciaram o funcionamento das políticas públicas para pescadores artesanais, o que influenciou nas suas ações e discricionariedade, e quais foram as consequências desses fatores. A análise envolve pesquisa qualitativa, com a utilização de dados primários e secundários. Constatou-se que os implementadores tiveram que, inicialmente, conhecer o público beneficiário, e no decorrer da implementação dos programas realizaram diversas adaptações às normas e regras para atender as especificidades dos pescadores artesanais locais. Essa discricionariedade dos burocratas de nível de rua, ou seja, as decisões tomadas por esses implementadores contribuíram para a reformulação das políticas públicas no município. Os burocratas que atuaram com maior inserção junto às famílias dos pescadores tiveram melhor compreensão da realidade, das limitações e das necessidades desse público, contribuindo para a inserção dos pescadores nas políticas públicas. Essa maior aproximação entre burocratas e pescadores influencia nos resultados da implementação da política pública.

Palavras-Chave: discricionariedade, implementadores, pescador artesanal.

\section{IMPLEMENTATION OF PUBLIC POLICIES IN CRAFT FISHERIES: THE ACTION OF STREET LEVEL BUROCRATS}

\begin{abstract}
This paper aims to analyze the performance of Street-level bureaucrats in the construction and implementation of public policies on Artisanal fishing in the municipality of Tramandaí/RS. These bureaucrats, called implementers, measure the relationship between citizens and the state, and can influence the implementation of

\footnotetext{
1 Graduada em Ciências (IEDB - Instituto Educacional Dom Bosco). Graduada em Ciências Contábeis (FEMA). Graduada em Planejamento e Gestão para o Desenvolvimento Rural - PLAGEDER (UFRGS). Mestre em Desenvolvimento Rural (UFRGS). E-mail: ivone.angst@ufrgs.br

2 Graduado em Agronomia. Mestre em Fitotecnia. Doutor em Fitopatologia. Professor da Universidade Federal do rio Grande do Sul no Programa de Pós-Graduação em Desenvolvimento Rural (PGDR) da Universidade Federal do Rio Grande do Sul (UFRGS). E-mail: fabiods@ufrgs.br
} 
public policies. The objective was to understand how these implementers influenced the operation of public policies for Artisanal fishing, which influenced their actions and discretion, and what were the consequences of these factors. The analysis involves qualitative research, with the use of primary and secondary data. It was found that the implementers had to initially know the beneficiary public and during the implementation of the programs made several adaptations to the norms and rules to meet the specificities of local Artisanal fishing. This discretion of the street level bureaucrats, that is, the decisions taken by these implementers, contributed to the reformulation of public policies in the municipality. The bureaucrats who worked more closely with the families of fishermen had a better understanding of the reality, limitations and needs of this public, contributing to the insertion of fishermen into public policies. This greater approximation between bureaucrats and fishermen influences the results of the implementation of public policy.

Keywords: artisanal fishing, discretion, frontline implementers.

\section{INTRODUÇÃO}

A implementação das políticas públicas é compreendida como um processo autônomo onde decisões são tomadas e não somente implementadas e que contribui inclusive, para orientar novas políticas (SILVA; MELO, 2000). Os responsáveis pela implementação, ou burocratas de nível de rua, são os atores que transformam os processos e que, segundo Lipsky (1980), além de exercerem a discricionariedade nas decisões relacionadas aos cidadãos, suas decisões individuais tornam-se o comportamento da agência pela qual respondem e que representam.

$\mathrm{Na}$ discussão das políticas públicas implementadas para a pesca no Brasil, destaca-se, neste estudo, a atenção para a pesca artesanal. Esta modalidade de pesca é realizada no Brasil por populações costeiras e ribeirinhas que vivem e reproduzem suas condições de existência na pesca, com pequena produção mercantil, vivendo exclusiva ou quase exclusivamente da pesca (DIEGUES, 1983), caracterizando-se como uma importante atividade econômica. Poucas foram as políticas públicas voltadas às necessidades dos pescadores artesanais, sendo que esta categoria permaneceu sem reconhecimento ou definição jurídica por muito tempo. Em 2003, a categoria profissional foi objeto de regulamentação específica, mas somente com a lei 11.326/2006 e posteriormente com a Lei 11.959/2009, o seu novo regime legal foi efetivado, enquadrando o pescador no regime de economia familiar, tais quais os agricultores familiares. Até então, as políticas públicas eram direcionadas quase que exclusivamente à pesca industrial ${ }^{3}$.

A pesca no Brasil apresentou três períodos de gestão ${ }^{4}$ que influenciaram a atividade e a formulação de políticas públicas para a categoria. Durante esses períodos, as ações por parte dos governos eram centradas ora no desenvolvimento

\footnotetext{
${ }^{3}$ Pesca industrial é a desenvolvida em águas marinhas, costeiras e oceânicas com embarcações com mais de duas toneladas de registro bruto (HAIMOVICl, et al. 2004).

${ }^{4}$ Os três períodos distintos são: 1) nos anos de 1962 e 1989 o controle da pesca foi pela Superintendência do Desenvolvimento da Pesca; 2) entre 1989 e 1998, a vigência do Instituto Brasileiro do Meio Ambiente e dos Recursos Naturais Renováveis (IBAMA) - teve a responsabilidade exclusiva da gestão da pesca no Brasil; 3) entre 1998 e 2003 foi o período de divisão de competências entre o Ministério do Meio Ambiente (MMA) e o Ministério da Agricultura, Pecuária e Abastecimento (MAPA) (AZEVEDO; PIERRI, 2014).
} 
industrial do setor, ora na conservação e preservação dos recursos pesqueiros que tinha poucas ações de incentivo ao desenvolvimento e fomento à atividade. Esse quadro repercutiu em dificuldades de acesso às políticas públicas por parte dos pescadores artesanais que não possuíam garantias materiais necessárias para acessar o crédito junto às instituições financeiras. Diante deste contexto, a maioria dos pescadores artesanais ficou em condições precárias de vida, resultando no seu empobrecimento, além de enfrentar a concorrência desigual com a pesca industrial e a aquicultura empresarial (GRAZIANO DA SILVA, 1982, AZEVEDO; PIERRI, 2014;).

$\mathrm{Na}$ década de 1990, algumas políticas foram dirigidas à pesca artesanal, tais como o Programa Nacional da Agricultura Familiar - PRONAF e políticas estaduais (no âmbito do estado do Rio Grande do Sul), como o Fundo de Amparo ao Pequeno Estabelecimento Rural (FEAPER) e o Programa RS Rural Pesca Artesanal. Este conjunto de incentivos financeiros, aliado à extensão do seguro desemprego ao pescador artesanal pela Lei no 8.287 de 20 de dezembro de 1991, passou a incluir o pescador artesanal na agenda de políticas públicas (HELLEBRANDT et al. 2012).

Em 2003 foi criada a Secretaria Especial de Aquicultura e Pesca (SEAP) com o objetivo de promover o fomento à atividade pesqueira e uma posição mais ativa do Estado. Neste mesmo ano, foi criado o Conselho Nacional de Pesca (CONGAPE) que é um órgão colegiado de caráter consultivo e as Conferências Nacionais com a finalidade de aferir as demandas de diferentes segmentos da sociedade civil, destacando a participação e espaços de interlocução com a sociedade civil ligada ao setor. Em 2009 foi criado o Ministério da Pesca e Aquicultura e, concomitantemente, aprovou-se o novo marco legal para a pesca no país, ou seja, a Lei no 11.959 que instituiu a Política Nacional para o Desenvolvimento Sustentável da Aquicultura e da Pesca (AZEVEDO; PIERRI, 2014).

No contexto histórico da atividade pesqueira, o Estado teve o papel principal de atuação. A criação, elaboração e implantação das políticas públicas para a pesca tiveram o enfoque dos interesses governamentais, na sua maioria. Esse processo das políticas públicas passa a ser cada vez mais impactada por influências externas (seus agentes, a burocracia, a acomodação de interesses políticos), mas também por influências externas (como os movimentos sociais).

No município de Tramandaí/RS, com a presença de pescadores profissionais artesanais que fazem da pesca a sua principal atividade socioeconômica, é recente a história de políticas públicas específicas para a pesca. E é esse o campo empírico no qual está evidenciado este trabalho.

Posto isto, este artigo tem por objetivo analisar a atuação dos burocratas de nível de rua na construção e implementação do Programa RS Rural Pesca Artesanal e Programa Nacional de Fortalecimento da Agricultura Familiar (Pronaf) no município de Tramandaí/RS, de modo a compreender como influenciam seu funcionamento e como agem, o que influencia suas ações e discricionariedade e quais as consequências desses fatores para a implementação das políticas públicas.

A coleta de dados baseou-se no levantamento documental sobre o Programa RS Rural e o Programa Nacional de Fortalecimento da Agricultura Familiar (Pronaf) e em entrevistas semiestruturadas, sendo, cinco entrevistas com os técnicos da EMATER, da prefeitura municipal e das instituições financeiras, responsáveis pela execução dos programas e 21 entrevistas com pescadores artesanais no período de março a dezembro de 2016. Foi realizada uma análise dos dados coletados para entender os fatores apontados na literatura e que influenciaram os casos estudados. Dessa forma, utilizaram-se as observações e 
ponderações dos pescadores e burocratas (técnicos) para perceber como aconteceram as influências destes.

Este artigo está organizado em duas seções principais, além desta introdução e da conclusão. Na segunda seção discute-se os elementos conceituais sobre implementação de políticas públicas, burocratas de nível de rua e a influência de seu poder discricionário. Na terceira, apresenta-se, a regulamentação das políticas do RS Rural e Pronaf e discute-se o modo como as mesmas são implementadas. Na quarta, são apresentadas as considerações finais.

\section{A IMPLEMENTAÇÃO DAS POLÍtICAS PÚBLICAS: ELEMENTOS CONCEITUAIS}

Várias definições são encontradas na literatura sobre o que seja política pública. Muller (2002) traz as contribuições de Mény e Thoenig (1989) pela sua amplitude nos elementos de definição, tais como: uma política pública está constituída por um conjunto de medidas concretas; compreende decisões e formas de atribuição dos recursos com natureza mais ou menos autoritária; se insere em um marco geral de ação; tem um público definido; estipula metas ou objetivos.

Souza (2006) aponta que as mais diversas definições de políticas públicas convergem para o governo, o locus onde acontecem os embates em torno de interesses e preferências. Esta autora também destaca que, ciente da definição, vale considerar que as políticas públicas repercutem na economia e nas sociedades, sendo assim, há inter-relações entre Estado, política, economia e sociedade.

Para Costa (2015), as políticas públicas refletem a natureza conflitiva de cada sociedade, sendo fundamental levar em conta as realidades sociais e históricas, culturais e identitárias de cada sociedade que tem sua história própria e com isso desafios diferentes. Isso evidencia que o campo das políticas públicas é extremamente heterogêneo.

A política pública, segundo Souza (2006), se apresenta como um ciclo com vários estágios. Estes são: definição de agenda, identificação de alternativas, avaliação das opções, seleção das opções, implementação e avaliação. Entretanto, nesses estágios, segundo Dias e Matos (2012), há uma constante interação recíproca dos atores, das restrições, das decisões e dos resultados.

Enfatizando a implementação de políticas públicas, Wu et al. (2014, p. 98) aponta que este estágio "é um processo dinâmico que envolve elementos de todas as "fases" anteriores da criação de políticas e todas as incertezas e contingências que elas podem acarretar". É na implementação que as decisões políticas se traduzem em ações que colocarão em prática a política elaborada (WU et al.,2014; FREY, 2000)

E quando se coloca em prática uma política pública, Lotta (2010) destaca que podem ser identificadas duas perspectivas de análise, ou seja, a top-down e botton-up, que podem ser opostas ou complementares entre si. Já Rodrigues (2016) cita que na literatura é apresentado um terceiro modelo de implementação, o híbrido.

O modelo top-down corresponde à concepção tradicional do trabalho administrativo que se desenvolve de cima (top) para baixo (down) ou do centro para a periferia (DIAS; MATOS, 2012). Para os adeptos da visão top-down, a implementação começa onde a política acaba, sendo assim um processo de colocar os programas políticos em prática. Nessa perspectiva, não há espaço para o exercício da discricionariedade por parte dos implementadores, onde os planos serão implementados exatamente como foram concebidos (LOTTA, 2010). Esse modelo, para Rodrigues (2016), não considera as questões relativas à 
implementação e as influências do ambiente onde estão acontecendo e Lipsky (2010) salienta que esse modelo não leva em conta os aspectos comportamentais dos implementadores quando da tomada de decisões.

Já no modelo bottom-up se considera a partir de onde existe o problema, um processo ascendente, de baixo para cima (DIAS; MATOS, 2012). Esse modelo observa o processo de criação de política como continuum, tendo modificações em todo o processo de traduzir as intenções em ações, onde o processo de implementação transforma e adapta as políticas originais (LOTTA, 2010). Nesse o modelo, os burocratas de nível de rua (street-level bureaucrats) têm discricionariedade na implementação da política e na interação entre eles e o cidadão, a política é modificada e aperfeiçoada (LIPSKY, 1980).

Jann e Wegrich (2007) propõem sintetizar os dois modelos, reforçando-os nas chamadas teorias híbridas. Rodrigues (2016) corrobora dizendo que alguns autores defendem a necessidade de combinar os dois modelos e que salientam a importância da visão top-down ao olhar para a política oficial que define a arena onde os processos acontecem, os papéis dos principais atores e as ferramentas que podem ser usadas para adquirir e oferecer recursos. Complementarmente, Barrett e Fudge (1981) apontam a necessidade de olhar para os ajustes realizados nos programas, levando em conta todo o contexto envolvido, numa visão bottom-up.

Para Dias e Mattos (2012), a implementação é compreendida como um processo autônomo onde decisões são tomadas e não somente implementadas e que contribui inclusive, para orientar novas políticas, servindo de fonte de informação para a formulação de políticas públicas. A implementação das políticas públicas ocorre através de redes de agentes públicos e também por agentes não governamentais, e quase nunca está a cargo de um agente apenas, tornando-se assim um campo interorganizacional (SILVA; MELO, 2000).

Considerando esses debates, focar-se-á nos responsáveis pela implementação das políticas públicas para os pescadores artesanais, ou seja, os atores que transformam os processos e que podem fazer uso da discricionariedade.

\subsection{OS IMPLEMENTADORES DE POLÍTICAS PÚBLICAS: OS BUROCRATAS DE NÍVEL DE RUA}

A questão da burocracia foi inicialmente discutida por Max Weber (1947), que a conectava com a análise dos tipos de autoridade. Para este autor, com a evolução da sociedade industrial moderna e o desenvolvimento do sistema de administração do Estado, passou a associar essa autoridade à racionalidade-legal. Essa racionalidade-legal se constitui sobre a crença na legalidade dos padrões de regras normativas e na permanência de um sistema de burocracias fundamentado em leis e regras. Nesse modelo, o burocrata é um executor de serviços sem questioná-los, sem ter espaço de exercício da discricionariedade (LOTTA, 2010).

Com a modernização da atuação e do papel do Estado, novos modelos teóricos e pesquisas práticas de análise do papel dos burocratas surgiram, ficando visível que o papel dos burocratas é complexo e que é difícil separar questões e ordem técnica ou política. Nas democracias contemporâneas, os burocratas não só administram, mas também participam da tomada de decisão juntamente com os políticos (LOTTA, 2010).

Para Lotta (2010) os estudos mais destacáveis sobre a atuação dos burocratas implementadores na fase da implementação da política pública foi de Lipsky (1980) sobre os Street-Level Bureaucracy. Esses agentes que atuam na linha de frente são denominados por Lipsky (1980), como burocracias de nível de rua e os 
define como as agências nas quais os trabalhadores interagem diretamente com os cidadãos no curso de suas tarefas (LIMA, D'ASCENZI, 2013).

A interação com os cidadãos também é citada por Meyers e Vorsanger (2010) e Vallès (2008), afirmando que os agentes que atuam na linha de frente são os que têm sua interface entre os cidadãos e o Estado, podendo influenciar a execução das políticas públicas (DIAS; MATOS, 2012, p. 82). Lipsky (1980) corrobora afirmando que os burocratas de nível de rua quando, na implementação da política pública, formatam seus resultados através da interpretação das regras e da alocação de recursos escassos, podendo limitar a vida e as oportunidades dos cidadãos.

Os resultados das políticas públicas dependem de muitos fatores, pois, segundo Pressman e Wildavsky (1984), no processo de implementação há uma multiplicidade de atores de diferentes tipos de organizações com interesses diversos que se agregam para operar a política. Estes interagem em uma trajetória de pontos de decisão nos quais suas perspectivas se expressam. Ao mesmo tempo, essa interação pode sofrer mudanças, pois os atores mudam com o passar do tempo, e com isso mudam as perspectivas e as percepções que um ator tem do outro.

Entretanto, O'Brien \& Li (1999) enfatizam que a discricionariedade dos implementadores é inevitável e pode ser desejável, já que esses atores detêm conhecimento das situações locais e podem adaptar o plano a elas (LIMA; D'ASCENZI, 2013, p. 103-104).

Os burocratas de nível de rua são agentes públicos que colocam em práticas as diretrizes, os objetivos, as políticas, programas e projetos do Estado para o bem-estar da sociedade em geral e por isso eles estão próximo e interagem com o público alvo, sendo dessa forma a imagem do poder público (RODRIGUES, 2016).

Nessa interação com o público-alvo na implementação da política pública, os burocratas podem tomar decisões em vista às situações não previstas na formulação dessa política e somente podem ser resolvidas no momento em que acontece a sua implementação, sendo dessa forma exercido o poder de discricionariedade dos burocratas de nível de rua (LIPKSY, 2010).

As decisões tomadas pelos implementadores são o exercício da discricionariedade, criando grande impacto sobre as políticas públicas implementadas uma vez que eles possuem autonomia no momento da implementação. Assim, Lipsky (1980) aponta que além de exercerem a discricionariedade nas decisões relacionadas aos cidadãos, as ações individuais dos burocratas tornam-se o comportamento da agência pela qual respondem e que representam. Dessa forma, mesmo que as dimensões políticas oficiais colocam alguns padrões de decisão e normas, esses burocratas ainda têm autonomia para decidir como aplicá-las (LOTTA, 2010).

\section{A IMPLEMENTAÇÃO DAS POLÍTICAS PÚBLICAS EM TRAMANDAÍ}

O município de Tramandaí está situado no Litoral Norte do Rio Grande do Sul, no contexto da Bacia Hidrográfica do Rio Tramandaí, que é o território delimitado pelo caminho das águas, desde seu ponto mais alto onde se situam nascentes e arroios (micro bacias) até a porção mais baixa em sua foz no oceano, através de conexões superficiais entre afluentes e o rio principal.

Tramandaí possui uma orla de $12 \mathrm{~km}$ de extensão e sua sede está situada à praia e ao sul da foz do rio Tramandaí e está a uma distância de $118 \mathrm{~km}$ de Porto Alegre, capital do estado do Rio Grande do Sul. Há no município três ambientes distintos de pesca, onde, adentrando no continente, os estuários, rios e lagoas de água doce. Este ambiente apresenta uma condição estuaria que favorece a criação 
de diversas espécies aquáticas, o que fez com que as principais comunidades de pescadores ali se estabelecessem, razão pela qual a pesca neste território sempre teve grande importância econômica (CASTRO; MELLO, 2013; COTRIM, 2008).

Figura 1 - Localização do município de Tramandaí e regiões com pescadores

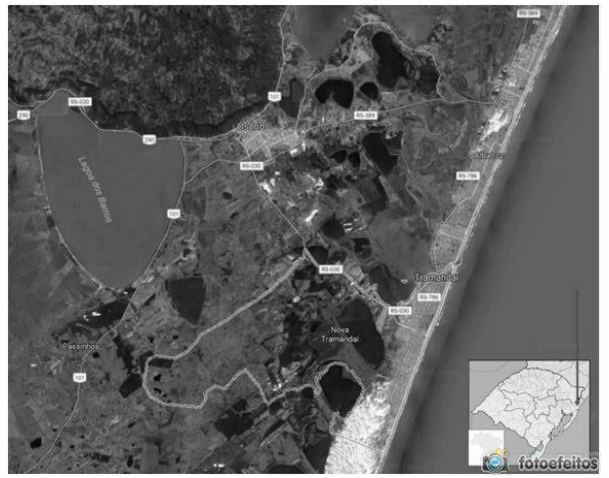

Fonte: Google Maps; Wikipedia (2017)

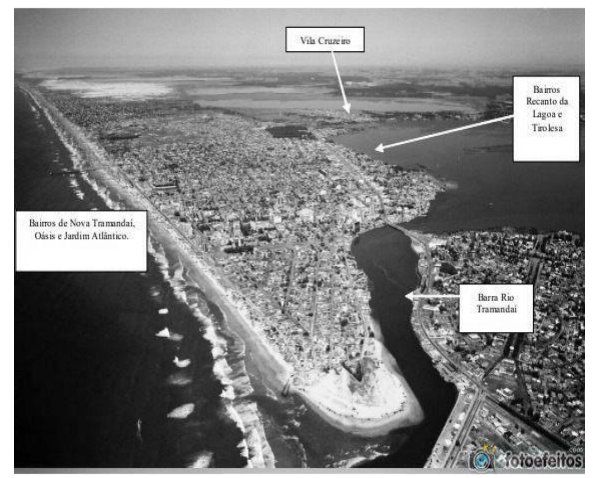

COTRIM (2008)

Nas últimas décadas, as comunidades de pescadores sofreram impactos com o crescimento urbano e o avanço do turismo uma vez que resultou em modificações nas condições ambientais dos locais de pesca. A poluição ambiental contribuiu para a redução dos estoques pesqueiros, gerando consequentemente a fragilidade econômica dos pescadores. Ao mesmo tempo, foi priorizado pelas políticas públicas municipais o enfoque nos turistas e outras categorias, excluindo os pescadores artesanais da região na tomada de decisão (COTRIM, 2008).

$\mathrm{Na}$ atualidade, Tramandaí possui 404 profissionais na pesca profissional artesanal, conforme o número de Registro Geral de Pescador (RGP), emitido pelo Ministério da Agricultura, Pecuária e Abastecimento. Estes têm sua representatividade através da Colônia de Pescadores e Sindicato dos Pescadores e interagem com diversas entidades que tem suas ações voltadas à pesca.

O marco inicial da implementação das políticas públicas na pesca em Tramandaí foi com o Programa RS Rural Pesca Artesanal, no ano de 2000. Esse também é o marco para o início da atuação junto aos pescadores, de entidades e seus atores, estes de burocratas de nível de rua, que denominamos de extensionistas. Com o término do RS Rural Pesca Artesanal, os pescadores reivindicaram o acesso ao Programa de Fortalecimento da Agricultura Familiar (PRONAF). Posteriormente, os pescadores acessaram outras políticas públicas, entretanto, aqui neste estudo, estaremos evidenciando o RS Rural Pesca Artesanal e o Pronaf sendo que, primeiramente apresenta-se a regulamentação das políticas e posteriormente discute-se o modo como as mesmas foram implementadas.

\subsection{O PROGRAMA RS RURAL PESCA ARTESANAL}

O Programa RS Rural, que inicialmente foi denominado de Pró-Rural (Programa de Conservação dos Recursos Naturais e Combate à Pobreza e ao Éxodo Rural), teve como estratégia trabalhar o manejo dos recursos naturais, visando à melhoria da renda das comunidades rurais pobres (BRACAGIOLI NETO, 2014). Desenvolvido pela Secretaria da Agricultura e Abastecimento do Estado do 
Rio Grande do Sul no ano de 1997, com empréstimo do Banco Mundial (BIRD), contemplou agricultores familiares e agricultores assentados, pescadores profissionais artesanais, povos indígenas e comunidades remanescentes de quilombos (GARTNER; BASSI, 2007).

No Programa RS Rural foi dado o enfoque de participação das famílias nas decisões sobre os investimentos realizados e famílias beneficiadas, através dos DRP's (Diagnóstico Rápido Participativo) e dos CMDR's (Conselhos Municipais de Desenvolvimento Rural) (AGUIAR, 2011). Através dos CMDR's, as demandas eram apreciadas e aprovadas e tinham a incumbência de escolher a comunidade beneficiada e aprovar as ações do programa no município (TRENTIN, 2001).

A Associação Riograndense de Empreendimentos de Assistência Técnica e Extensão Rural (EMATER/RS) executava o programa, mediando o trabalho com os municípios e os grupos de pequenos agricultores beneficiários das ações. Os recursos para manter o programa eram oriundos de ajuda e cooperação internacional, transferência de recursos do orçamento do estado e dos municípios, contrapartidas dos beneficiários e por outras receitas eventuais que, por lei, vinculavam-se aos objetivos do programa (TRENTIN, 2001).

O Manual Operativo do programa (RIO GRANDE DO SUL, 2003) apontava a que o RS Rural Pesca Artesanal foi destinado ao pescador artesanal, através de projetos de geração de renda, infraestrutura social básica e manejo dos recursos pesqueiros, possibilitando a realização de ações integradas para o desenvolvimento social e ambiental das comunidades de pescadores.

\subsection{O PROGRAMA NACIONAL DE FORTALECIMENTO DA AGRICULTURA FAMILIAR (PRONAF)}

O Pronaf (Programa Nacional de Fortalecimento da Agricultura Familiar) surge num contexto de antigas reivindicações dos movimentos sociais do campo. No discurso governamental, essa nova política pública teria a missão de combater as desigualdades presentes até então nas políticas estatais que estimulavam a mudança da base técnica da agricultura do país. (AQUINO; SCHNEIDER, 2015).

O Pronaf foi instituído pelo decreto presidencial no 1.946 de 28 de junho de 1996, sendo que, segundo Haimoviciet et al. (2004), sendo que os pescadores artesanais foram contemplados no programa a partir da resolução do BACEN $n$. 2409 de 1997.

Em 2003, com a mudança institucional no Governo Federal, foram formuladas políticas públicas que passaram a contemplar uma maior diversidade de grupos sociais, com ênfase para as chamadas comunidades tradicionais, dentre as quais os pescadores artesanais (SCHNEIDER; CAZELLA; MATTEI, 2009). Com essa ampliação dos beneficiários, foi incluído no Plano Safra 2003/04 a criação do PRONAF Pesca com o objetivo de apoiar os pescadores e proporcionar-lhes, de modo formal, o acesso ao sistema de crédito da mesma forma que os agricultores familiares já estavam contemplados.

De acordo com o Plano Safra 2015/2016, são várias linhas de crédito para os pescadores artesanais, tais como: Pronaf microcrédito, Pronaf mulher, Pronaf jovem, Pronaf para agregação de renda, e Pronaf agroindústria familiar. No Pronaf Custeio, o pescador financiar despesas feitas pela atividade de pesca durante 0 ano, tais como: combustível, gelo, mão de obra, manutenção da embarcação e do motor, dentre outros. No Pronaf Investimento, é possível financiar embarcações, motores, redes novas, guinchos, instalações para armazenagem, beneficiamento e comercialização do pescado e outros. 


\subsection{IMPLEMENTAÇÃO DO PROGRAMA RS RURAL PESCA ARTESANAL}

Para descrever a implementação do Programa RS Rural Pesca Artesanal na pesca em Tramandaí, enfatiza-se a questão do olhar dos burocratas de nível de rua e dos pescadores artesanais na execução das ações da Política. Procura-se então compreender como aconteceu, na prática, a implementação do Programa RS Rural Pesca Artesanal em Tramandaí.

O Programa RS Rural Pesca Artesanal foi executado pelos burocratas de nível de rua da extensão rural do Estado, através da EMATER/RS, dos agentes financeiros e da Prefeitura Municipal. As ações da EMATER/RS são voltadas à agricultura e aos povos tradicionais, estruturada em nível de Estado e dispõe de escritórios nos municípios para a prestação de serviços de assistência técnica e extensão rural. Os burocratas dessa instituição têm um suporte técnico, capacitação permanente e troca de conhecimentos e experiências entre os diversos funcionários da instituição de todo o Estado, o que é importante para a constante atualização das temáticas na qual atuam. Os burocratas implementadores da Prefeitura Municipal possuem menor suporte técnico organizacional, sendo que sua atuação se reforçou com o trabalho conjunto com os burocratas da EMATER.

O Programa RS Rural Pesca Artesanal é a política pública referenciada pelos burocratas de nível de rua como um marco inicial de acesso as políticas pelos pescadores artesanais de Tramandaí/RS. Na fala do burocrata da EMATER/RS, "foi o divisor, o primeiro programa voltado aos pescadores artesanais em Tramandaí". O escritório da EMATER/RS foi instalado no município no ano de 1990, mas somente no ano de 2000, seus técnicos iniciaram as ações com os pescadores artesanais.

Para a operacionalização do Programa RS Rural Pesca Artesanal, a Prefeitura Municipal assinou um termo de adesão com o governo do Estado e implementou os critérios exigidos, tais como a criação da Secretaria Municipal da Pesca e Agricultura, as deliberações através do Conselho Municipal de Desenvolvimento Rural e criação de um fundo municipal de desenvolvimento rural. Dessa forma, de acordo com Wu et al. (2014), a implementação afeta e é afetada por diversos de atores, que definem problemas e soluções em um determinado domínio de políticas públicas.

Para implementar o Programa RS Rural, os extensionistas da EMATER/RS, que até naquele momento trabalhavam somente com os agricultores, receberam treinamento de um dia pela empresa para atuar com pescadores artesanais. Os extensionistas da recém-criada Secretaria Municipal da Pesca da Prefeitura Municipal também não tinham atuação junto aos pescadores, o que os estimulou a um trabalho conjunto com extensionistas da EMATER/RS.

Esses burocratas implementadores, aos quais denominamos neste artigo, de extensionistas, não conheciam os pescadores e suas comunidades e, para se aproximar desses atores e conhecê-los, a Prefeitura Municipal contratou temporariamente uma pescadora do município que tinha uma atuação de liderança junto a sua categoria, sendo cedida para atuar junto ao escritório da EMATER/RS, que coordenaria a implementação do programa. Essa pescadora relata sobre sua contratação: "eu era pescadora, conhecia todos os pescadores e eles confiavam em mim, então eu acompanhei os técnicos da EMATER/RS para eles conhecerem os locais de moradia dos meus colegas".

Essa discussão provoca a reflexão da política no modelo top-down, no sentido de que as políticas públicas foram formuladas para os pescadores de modo geral. Mas cada região tem suas especificidades e os burocratas até aquele momento não conheciam os beneficiários. O poder discricionário dos burocratas de nível de rua é evidenciado quando reconhecem esse fato e a importância da 
liderança dessa pescadora de modo que foram buscar subsídios sobre os beneficiários com quem realmente teria esse conhecimento e pudesse contribuir para a aproximação com o público beneficiário da política pública. Isso é demonstrado na fala do burocrata da EMATER/RS, "essa liderança permanece na atualidade, sendo referência dos pescadores na mobilização de ações".

A primeira reunião com os pescadores artesanais foi realizada no mês de abril de 2000, junto a Associação dos Moradores da comunidade Cruzeiro do Sul, onde residiam muitos pescadores. As primeiras sensações e impressões são relatadas pelo extensionista da EMATER, manifestando que não imaginava sobre os problemas e dificuldades da categoria, nem suas necessidades. Os burocratas se deparam com diferentes linguagens, diversos conhecimentos e significados que se tornam visíveis a partir de uma política pública que amplia o seu público beneficiário e estimula a participação dos pescadores. Isto mostra que o extensionista procurou entender a lógica de ação dos atores, as forças presentes nessa localidade a fim de diagnosticar os diversos desafios, colocando-se na mesma posição estrutural que os pescadores, facilitando a interação e comunicação.

Quando os agentes políticos formulam as políticas públicas, nem sempre compreendem que para colocar essas iniciativas em ação, surgem vários contextos que podem limitar e exigir formas de adaptação dos burocratas que as implementarão, utilizando-se do poder discricionário. Para o extensionista da EMATER/RS, os atores a quem se destinam as políticas públicas têm seus modos de vida e reivindicam a participação nas decisões da implementação, de modo que se adaptem às suas necessidades e anseios. Os extensionistas se mostraram solícitos, demonstrando estar disponível para resolver os problemas dos pescadores.

A atuação desses extensionistas ocorreu em diversos aspectos que envolveram a família (saúde, alimentação, políticas públicas, saneamento, etc.), estabelecendo um vínculo com os pescadores. Esses burocratas buscaram se mostrar em igual posição do pescador de modo que sua ação fosse legitimada pela igualdade e proximidade.

A metodologia de trabalho adotada e consolidada pelos extensionistas da EMATER/RS na implementação do Programa RS Rural foi a realização do DRP e as decisões aprovadas pelos CMDR, sendo o que Aguiar (2011) aponta que o DRP e os CMDR foram espaços que promoveram a participação das famílias nas decisões dos investimentos realizados e das famílias beneficiadas.

Foram realizados três DRP's no período entre 2001 e 2002, sendo o primeiro nos Bairros Cruzeiro do Sul I e II, o segundo DRP nos bairros da Barra, Centro, Centro-lagoa, São Francisco I e II e o terceiro DRP na Zona Sul. O extensionista da EMATER/RS relata a importância do uso da metodologia participativa,

“[...] para nós foi muito importante o DRP, primeiro porque foi uma surpresa muito grande. Quando pensamos a metodologia do 'mapa', os pescadores fizeram o mapa da casa deles até a lagoa - esse era o mundo deles - e nós pensávamos que eles iriam desenhar o seu mapa apontando sua ligação com comércio, bancos." (extensionista da EMATER/RS)

Para este extensionista, esses diagnósticos foram importantes para compreender as rotinas, o cenário institucional aos quais os pescadores são interligados, a construção do mapa da comunidade a partir da visão dos mesmos, a história e o itinerário de desenvolvimento, os sistemas de pesca realizados, as 
rotinas diárias das famílias e levantamento sobre a saúde e alimentação das famílias. Percebe-se que os extensionistas atuaram de forma a traduzir os termos técnicos para termos mais comunitários, na tentativa de facilitar a compreensão dos pescadores.

A metodologia participativa utilizada pelos extensionistas também permitiu com que compreendessem como os pescadores procedem com a comercialização do pescado. Esta comercialização era realizada na venda direta ao consumidor quando saia do local da pesca (lagoa e mar) e nas vizinhanças quando o pescador retornava para casa e aos intermediários (peixarias); apenas alguns pescadores possuíam equipamento de refrigeração na sua residência, armazenando o pescado para venda posterior, barganhando preços. Os extensionistas perceberam que os pescadores necessitavam de recursos para adquirir equipamentos de refrigeração do pescado.

Outro aspecto observado pelos extensionistas através dos DRP's, foram os procedimentos no manuseio do pescado, sem as normas adequadas na limpeza dos peixes. Isso estimulou os extensionistas a realizarem capacitação aos pescadores para melhoria da qualidade de processamento e manuseio do pescado.

As principais demandas comunitárias levantadas nos DRP"s foram: a necessidade de ampliação de organização comunitária, o acesso a políticas públicas para aquisição de equipamentos de pesca e a participação dos pescadores na gestão dos recursos pesqueiros. Segundo a pescadora "Fulana de tal", "no DRP a gente se reuniu, os técnicos vinham e nós falávamos dos nossos problemas, a gente queria projetos". Numa heterogeneidade de pescadores, os extensionistas perceberam diversos projetos individuais, o que os estimulou a incluir na sua agenda de trabalho o enfoque de atendimento à categoria dos pescadores.

A realização do DRP também tornou visível a realidade dos equipamentos utilizados na pesca, sendo que poucos pescadores eram proprietários de motores, e estes equipamentos apresentavam medida de potência baixa (de 4HP) e fabricados com material de metal. A vida útil desse motor era de 2 a 3 anos que, além da medida de potência baixa, apresentava rapidamente problemas de corrosão. Da mesma forma, poucos pescadores possuíam equipamentos de refrigeração para o pescado e estes eram precários e velhos. Esse quadro modificou-se gradativamente através do acesso às políticas públicas, de modo que os equipamentos de pesca e armazenamento são mais potentes e modernos.

Através do Conselho Municipal de Desenvolvimento Rural foram analisados e aprovados os projetos do programa que, segundo o extensionista da EMATER/RS, "num primeiro momento dizia que não tinha condições de avaliar projetos de pescadores, pois não conheciam nada sobre eles".

Percebe-se que pela perspectiva top-down tem-se o olhar para a política oficial que define a arena onde os processos acontecem, os papéis dos principais atores e as ferramentas que podem ser usadas para adquirir e oferecer recursos. Entretanto, torna-se importante a complementariedade, conforme salientam Barrett e Fudge (1981) sobre a necessidade de olhar para os ajustes realizados nos programas, levando em conta todo o contexto envolvido, numa visão bottom-up, ou seja, posteriormente foi criado um Conselho específico para pesca.

Para a liberação dos recursos do Programa RS Rural exigia-se a organização da categoria. Os extensionistas da EMATER/RS e da Prefeitura Municipal propuseram aos pescadores que a liberação dos recursos fosse através da Associação dos Pescadores existente no município. Essa Associação era composta por pescadores profissionais industriais, artesanais e amadores. Essa proposta não foi aceita pelos pescadores, determinando assim um processo de escolha desses atores na decisão de organizar um maior número de associações de 
acordo com suas áreas de domínio. Assim, os extensionistas se adaptaram às escolhas dos pescadores, de modo que se efetiva aos moldes do bottom-up, ou seja, de baixo para cima.

Muitos pescadores relatam que a formação de associações foi um momento importante porque se sentiram mais fortes, lutando conjuntamente, decidindo, mobilizando e fazendo parte do processo de organização da categoria. Entretanto, essa novidade também trazia à tona as dificuldades de compreensão e posteriormente até desconfianças em relação à destinação dos recursos. O extensionista da EMATER/RS relata que quando o pescador solicitava orçamento no comércio dos materiais que pretendia incluir no projeto, o valor era diferente daquele quando os burocratas da instituição verificavam o orçamento. Esses extensionistas perceberam posteriormente que isso foi pelo fato de que, as empresas, entendendo que a EMATER/RS frisava da necessidade de nota fiscal de cada produto comercializado, emita um orçamento superior.

As orientações sobre as regras e normas que envolviam os trâmites burocráticos da implementação da política pública não foram totalmente compreendidas pelos pescadores. Isso também é perceptível no depoimento do extensionista da EMATER/RS "para comprar o motor, tivemos que buscar preços em Porto Alegre, pois em Tramandaí havia lojas com pouca opção. Entre a elaboração do projeto e a liberação do recurso, houve aumento do preço dos materiais e por isso o pescador tinha que pagar a diferença".

Os extensionistas também relatam sobre as dificuldades enfrentadas em relação aos orçamentos que o programa exigia referente aos materiais propostos para aquisição pelos pescadores. Nem sempre o melhor preço correspondia à marca desejada pelo pescador, sendo que os burocratas sentiram dificuldades de melhorar a compreensão do processo para aqueles.

O significado da política pública na vida desses atores é evidenciado por eles quando relatam que, com os equipamentos adquiridos, diminuiu a penosidade do trabalho e garantiu maior segurança na realização do seu trabalho. Salientam também que, percebendo a possibilidade de recursos para a aquisição de materiais e equipamentos, se mobilizaram para atingi-los. Isso é visível na fala do Pescador "Sicrano de tal" "recebi um motor, ele durou sete anos e para pagar, tinha carência de dois anos e rebate. Antes era a remo e motor fraco estragava, aí era um perigo estar na lagoa". Relatam também que os extensionistas da EMATER/RS foram fundamentais para que tivessem acesso à política e que tinham um trabalho permanente com eles. Essas considerações também foram percebidas por AlmeidaSantos, Dani, Araújo, Matias-Pereira (2016) que apontam maiores escalas de satisfação pela atuação dos técnicos da EMATER, de forma condizente com as necessidades do público e em conformidade com aspectos legais.

O programa apresentava também um viés socioambiental, com atuação dos burocratas no sentido de propor um projeto para o destino adequado dos resíduos do pescado, pois durante a realização dos DRP e das diversas visitas aos pescadores, ficou visível que os resíduos eram jogados diretamente nas lagoas. Assim, foi elaborado o projeto "Relatório Final: aproveitamento dos resíduos de pescados de Tramandaí/RS", com o objetivo de apresentar o diagnóstico da situação, as alternativas para o processamento de resíduos de pescados, visando a obtenção de subprodutos com maior valor de mercado, e uma descrição da unidade de industrialização padrão para Tramandaí. O estudo foi considerado importante pelos extensionistas para mostrar que há um grande volume de resíduos de pescados, e se pretendia concretizar um programa Municipal de processamento dos resíduos, o que não se efetivou por diversas dificuldades encontradas, entre as quais a falta de recursos para a execução do mesmo. 
Através da execução da política pública e a participação dos pescadores nas discussões dos DRP, os extensionistas perceberam que havia uma demanda represada pelos pescadores sobre o regramento da pesca no estuário de Tramandaí. Dessa forma, os extensionistas da EMATER/RS e Prefeitura Municipal sentiram-se estimulados a uma ação conjunta de conversas com o IBAMA entre os anos 2003 e 2004. Essas discussões contribuíram para se construir a portaria IN17/20045 , do Ministério do Meio Ambiente, que começou a regrar a pesca na Bacia do Rio Tramandaí.

O trabalho com as pescadoras artesanais através do uso da técnica de artesanato em escama de peixe nos anos de 2004 e 2005 foi outra ação que os burocratas de nível de rua propuseram por perceber um potencial de renda futura. $A$ capacitação das pescadoras foi financiada pela Prefeitura Municipal, como contrapartida ao Programa RS Rural Pesca Artesanal. Esse projeto teve o intuito de resgatar o tipo de artesanato da cultura açoriana (presente na região) para proporcionar uma oportunidade de inclusão da mulher pescadora na sociedade e gerar fonte de renda familiar. Atualmente, são quatro pescadoras artesanais que confeccionam e comercializam artesanato com o uso das escamas de peixe.

$\mathrm{Na}$ execução do Programa RS Rural Pesca Artesanal, os extensionistas, através das metodologias participativas estimularam a participação dos pescadores, resultando num espaço de sua afirmação, mostrando quem realmente são, onde estão localizados e quais seus anseios. A partir dessa participação na execução do programa, os pescadores começaram a reivindicar uma maior interface das instituições para com a categoria, através dos seus extensionistas.

Quanto à forma associativa, mesmo que nem todas as associações persistiram até a atualidade, foram significativas em dado momento para a mobilização conjunta desses atores. E há de se considerar que a pressão exercida pelos pescadores nos diversos momentos de participação resultou em maior comprometimento por parte dos burocratas de nível de rua que se envolveram na pesca.

\subsection{A IMPLEMENTAÇÃO DO PRONAF}

Após o término do Programa RS Rural Pesca Artesanal, aconteceu uma corrida dos pescadores para financiamento. Aconteceram mobilizações dos pescadores junto à Agência do Banco do Brasil, reivindicando liberação de recursos. O Banco do Brasil até o momento não tinha elaborado projetos para esse público. Para atender as reivindicações da categoria dos pescadores, os extensionistas da agência financeira buscaram suporte técnico com os burocratas da EMATER/RS para entender como elaborar um plano de custeio. Esses implementadores da EMATER/RS relatam que "essa dificuldade inicial do banco foi similar à dificuldade que nós enfrentamos quando do início do trabalho com os pescadores artesanais". Dessa forma, foram elaborados planos de custeio para camarão, Plano de Custeio para Bagre, entre outros, uma vez que cada forma de pesca necessita de equipamentos diversos e com períodos diferentes.

$\mathrm{Na}$ fase de implementação foram necessárias adaptações do programa às situações concretas locais. Os burocratas financeiros se depararam com uma situação diferente, ou seja, atender os pescadores artesanais, um público diferenciado dos demais já atendidos pela instituição, ressaltando o poder

\footnotetext{
${ }^{5}$ A IN17/2004 regra proibição da pesca em alguns locais específicos da bacia, regula algumas modalidades de pesca e petrechos, determina o período para a pesca de determinadas espécies e orienta o processo da licença ambiental, que é emitida pelo IBAMA (PERUCCHI, 2013, p. 118).
} 
discricionário dos burocratas. Ao mesmo tempo, demonstrou a capacidade de intervenção dos pescadores no sentido de pressionar os agentes financeiros a atenderem à sua categoria profissional, e adaptar a política às suas especificidades.

Os planos de custeio foram enquadrados como Pronaf Especial (Pronafinho), com exigência de formação de grupos de, no mínimo, três famílias (sistema de aval solidário, com somente uma cédula de quitação). Nessa modalidade (Pronafinho) não há necessidade de garantias, a não ser pela vinculação aos contratos de outros pescadores, ou seja, os contratos são efetuados em grupos de até cinco pescadores, que se responsabilizam uns pelos pagamentos dos outros beneficiários de seu grupo, pois se algum se tornar inadimplente, impossibilita o outro de acessar novos empréstimos.

Essa modalidade de financiamento foi realizada durante três anos, com cento e cinco beneficiados que se organizaram em trinta e um grupos. Houve uma inadimplência de aproximadamente vinte por cento $(20 \%)$ dos pescadores, criando um descrédito da instituição financeira em relação ao pescador. Essa inadimplência é apontada pelo extensionista da EMATER/RS, como um despreparo dos pescadores em selecionar os integrantes do grupo de financiamento comprometidos no pagamento do empréstimo. Afirma também que a inadimplência se deve também pelo fato de os pescadores não estarem acostumados com os trâmites das agências financeiras. Segundo a fala de um pescador,

"Nós formamos um grupo de três pescadores, mas uma pessoa do grupo não pagou, então ficamos inadimplentes até hoje e por isso não consigo mais empréstimo no banco. O meu motor estragou, teria que comprar outro, mas não posso financiar. O pescador não estava preparado para financiamentos, as entidades deveriam ter preparado a gente melhor sobre isso, só mais tarde a EMATER fez curso para orientar." (Pescador)

Entretanto, os extensionistas envolvidos nessa política reconhecem que tiveram dificuldades de perceber essas dificuldades de compreensão dos pescadores, principalmente sobre a cobrança de taxa para a manutenção da conta bancária através da qual o recurso era liberado, o uso adequado do talão de cheque e cartão da conta. Dessa forma, relembramos que o modelo top-down, segundo Rodrigues (2016), não considera as questões relativas à implementação e as influências do ambiente onde estão acontecendo.

O extensionista da instituição financeira relata que o sistema de aval solidário foi repensado visto que, caso um membro do grupo não efetuasse o pagamento de sua dívida, todos do grupo ficariam inadimplentes. Assim, surgem situações não previstas na formulação da política e somente podem ser resolvidas no momento da implementação, sendo que dessa forma foi extinto o sistema de aval solidário, evidenciando que os burocratas escutaram as demandas dos pescadores e reformularam a política pública, exercendo o poder de discricionariedade dos burocratas de nível de rua conforme menciona Lipksy (2010). Entretanto, esse processo teve um período de adaptação, de modo que entre os anos de 2008-2012 praticamente não houve liberação de crédito para pescadores pelo Banco.

Posteriormente, sem aval solidário, a exigência passou a ser um fiador nos financiamentos. Entre os anos de 2011 e 2015, foram sessenta e nove (69) projetos do Pronaf, via banco do Brasil, elaborados pela empresa de assistência técnica e extensão rural. No ano de 2013, o Banco do Estado do Rio Grande do Sul S.A. (Banrisul) possibilitou crédito aos pescadores, via Pronaf Pesca onde houve 
aquisição de motores. Em 2015, Tramandaí possuía quatrocentos e dez pescadores profissionais artesanais cadastrados no Registro Geral de Pesca, porém, somente nove pescadores acessaram essa política pública.

Entretanto, com a alteração do aval solidário para fiador, os burocratas se depararam com outro entrave, pois a data de vencimento das parcelas do financiamento não coincidia com o período de maior renda dos pescadores. Diante das manifestações sobre a dificuldade de pagamento do financiamento pelos pescadores, os extensionistas, tanto da EMATER/RS como da instituição financeira, adequaram os projetos de modo que o vencimento dos financiamentos passou a ser no final do verão, onde o pescador tem a receita de vendas principalmente para veranistas, receita do seguro-defeso, venda da sua mão de obra para veraneio e também para os pescadores feirantes, a sua receita da venda do pescado na Feira anual do peixe (semana da páscoa). Assim, para Rodrigues (2016), pela perspectiva bottom-up, a política é vista como flexível e apta a se adequar a possíveis alterações, podendo levar a diferentes resultados.

As decisões tomadas pelos implementadores são o exercício da discricionariedade, criando mudanças sobre as políticas públicas implementadas uma vez que eles possuem autonomia no momento da implementação. Ao mesmo tempo, a criação de sistemas de financiamento formais exigiu mudanças e adaptações à cultura financeira do pescador, condições não consideradas no processo operacional das políticas públicas voltadas para públicos diferenciados.

\section{CONSIDERAÇÕES FINAIS}

Na implementação do Programa RS Rural Pesca Artesanal e do Pronaf na pesca em Tramandaí enfatizou-se a questão da participação dos burocratas de nível de rua.

Os implementadores, definidos como burocratas de nível de rua ou então extensionistas, da instituição EMATER/RS envolvidos nesses programas possuem suporte técnico, capacitação permanente e troca de conhecimentos e experiências constantes entre os diversos atores. Isso difere dos implementadores da Prefeitura Municipal, que possuem menor suporte técnico organizacional, sendo que sua atuação se reforçou com o trabalho conjunto com os extensionistas da EMATER/RS, e das instituições financeiras.

Os implementadores tiveram sua atuação de forma distinta, conforme a incumbência e atribuições de suas organizações na execução dos programas, mas suas ações foram realizadas de forma conjunta em diversos momentos.

Os programas de políticas públicas estavam disponíveis para serem implementados no município, mas não estava claro onde exatamente os beneficiários se encontravam. Num modelo top-down, as políticas públicas foram formuladas para os pescadores de modo geral, entretanto, cada região e grupo de beneficiários tem suas especificidades.

Portanto, os extensionistas realizaram atividades prévias à implementação da política, procurando entender como funcionava a pesca, as necessidades e o modo de vida desses cidadãos. Estas ações foram criadas, pensadas, formuladas e implementadas para dar conta das necessidades locais e demandado um esforço pessoal realizado pelos implementadores. Isso poderia ser dito como uma reformulação da política.

Os extensionistas em diversos momentos se colocaram na mesma posição estrutural que os pescadores, facilitando a interação e comunicação. Isso contribuiu para que entendessem a lógica de ação dos atores, as forças presentes e 
diagnosticar os desafios. Os burocratas se adaptaram às escolhas dos pescadores, de modo que se efetiva aos moldes do bottom-up, ou seja, de baixo para cima.

Os implementadores atuaram de forma a traduzir os termos técnicos para termos mais comunitários, na tentativa de facilitar a compreensão dos pescadores e se mostraram solícitos, demonstrando estar disponíveis para contribuir na solução dos problemas dos pescadores. Entretanto, os burocratas da instituição financeira tinham uma menor inserção no cotidiano dos pescadores, ao mesmo tempo em que, o contato com esse público acontecia somente nos momentos de acesso ao crédito. Assim, os agentes financeiros dispensaram menos atenção aos pescadores e demoraram a perceber que estes tinham dificuldades de compreensão das normas e regras de financiamentos e da instituição, como manutenção da conta bancária, a importância do pagamento do financiamento, o aval solidário.

Considera-se importante destacar as colocações de Jann e Wegrich (2007) e Rodrigues (2016) no sentido de combinar os dois modelos de análise da implementação, ressaltando a importância da visão top-down ao olhar para a política oficial que define a arena onde os processos acontecem, os papéis dos principais atores e as ferramentas que podem ser usadas para adquirir e oferecer recursos e, complementarmente, segundo Barrett e Fudge (1981), a necessidade de olhar para os ajustes realizados nos programas, levando em conta todo o contexto envolvido, numa visão bottom-up.

É importante que políticas públicas sejam conectadas com o saber dos pescadores e às especificidades regionais. Há uma heterogeneidade dos projetos no espaço local o que leva a pensar no tempo natural das pessoas, costumes dos grupos e suas relações sociais. Isto evidencia que os elaboradores das políticas públicas devem projetar e se preocupar como estas políticas chegam aos beneficiários.

Evidencia-se também o fato de que o domínio da arte da pesca dos atores pescadores e que não era do conhecimento dos implementadores. Retoma-se então a discussão da perspectiva bottom-up uma vez que, quando as políticas públicas são formuladas, diversos aspectos podem não ser percebidos, sendo que no momento da implementação, da ação efetiva é que afloram os entraves e as dificuldades e que na interface com os pescadores, podem contribuir para que futuras políticas públicas possam melhorar os aspectos que dificultaram o processo, sendo então a política reconstruída o tempo todo.

A discricionariedade da burocracia no contato com o cidadão é inevitável, de modo que foi necessário a barganha, adaptações e conhecer a realidade do pescador e suas necessidades. Em dados momentos, os implementadores usaram o poder de discricionariedade, modificando ou adaptando regras e normas dos programas de modo que facilitasse o acesso aos recursos das políticas públicas. Pode-se dizer que isso contribuiu para a reformulação da política pública.

\section{REFERÊNCIAS}

AGUIAR, M. D. S. Condições de vida, políticas públicas e efeitos no desenvolvimento rural: uma análise do Programa "RS Rural" no contexto das desigualdades Regionais no Rio Grande do Sul. 2011. Tese (Doutorado em Desenvolvimento Rural) - Programa de Pós-Graduação em Desenvolvimento Rural, Universidade Federal do Rio Grande do Sul, Porto Alegre.

ALMEIDA-SANTOS; P. S.; DANI, A. C.; ARAÚJO, J. L. A.; MATIAS-PEREIRA, J. Qualidade do serviço público para efetivação de políticas públicas para o 
desenvolvimento rural sustentável: levantamento em uma comunidade pesqueira local. Extensão Rural, v. 23, n. 4, p. 46-65, 2016.

AQUINO, J. R.; SCHNEIDER, S. O Pronaf e o desenvolvimento rural brasileiro: avanços, contradições e desafios para o futuro. In: GRISA, C.; SCHNEIDER, S. (Org.). Políticas públicas de desenvolvimento rural no Brasil. Porto Alegre: Editora da UFRGS, 2015. p. 53-82.

AZEVEDO, N. T.; PIERRI, N. A política pesqueira no Brasil (2003-2011): a escolha pelo crescimento produtivo e o lugar da pesca artesanal. Desenvolvimento e Meio Ambiente, Curitiba, v. 32, p. 61-80, dez. 2014.

BARRETT, S.; FUDGE, C. (eds). Policy and action. Methuen, London, 1981.

BRACAGIOLI NETO, B. Arenas públicas, participação e mediação social. 2014. Tese (Doutorado em Desenvolvimento Rural) - Programa de Pós-Graduação em Desenvolvimento Rural, Universidade Federal do Rio Grande do Sul, Porto Alegre, 2014.

CASTRO, D.; MELLO, R. S. P. (Org.). Atlas ambiental da bacia hidrográfica do Rio Tramandaí. Porto Alegre: Via Sapiens, 2013.

COSTA, V. Políticas públicas no Brasil: uma agenda de pesquisas. Revista Ideias, Campinas, v. 6, n. 2, p. 136-166, jul. 2015.

COTRIM, D. S. Agroecologia, sustentabilidade e os pescadores artesanais: O caso de Tramandaí (RS). 2008. Dissertação (Mestrado em Desenvolvimento Rural) Programa de Pós-Graduação em Desenvolvimento Rural, Universidade Federal do Rio Grande do Sul, Porto Alegre.

DIAS, R.; MATOS, F. Políticas Públicas: princípios, propósitos e Processos. São Paulo: Editora Atlas, 2012.

DIEGUES, A. C. S. Pescadores, camponeses e trabalhadores do mar. São Paulo: Editora Ática, 1983.

FREY, K. Políticas públicas: um debate conceitual e reflexões referentes à prática da análise de políticas públicas no Brasil. Planejamento e políticas públicas. Brasília: IPEA, vol. $212000 . \quad$ P. 211-259. Disponível em: http://www.ipea.gov.br/ppp/index.php/PPP/article/viewFile/89/158.

GARTNER, C.; BASSI, L. O Programa RS Rural como instrumento de apoio à conservação da biodiversidade. Resumos do II Congresso Brasileiro de Agroecologia. Revista Brasileira Agroecologia, v. 2, n. 1, fev. 2007.

GOOGLE. Tramandaí: Google Maps, 2017. Disponível em: https://www.google.com.br/maps/place/Tramanda\%C3\%AD+-+RS/@-29.9689167,$50.2972946,35788 \mathrm{~m} / \mathrm{data}=! 3 \mathrm{~m} 1$ ! $1 \mathrm{e} 3 ! 4 \mathrm{~m} 5 ! 3 \mathrm{~m} 4$ !1 s0x95186cd1 ca4eb565:0x3fb778da a806a18a!8m2!3d-29.9846105!4d-50.1326727. Acesso em: jul. 2017.

GRAZIANO DA SILVA, J. A modernização dolorosa: estrutura agrária, fronteira agrícola e trabalhadores rurais no Brasil. Rio de Janeiro: Zahar, 1982. 
HAIMOVICI, M. et al. Diagnóstico da pesca no litoral do estado do Rio Grande do Sul. $2006 . \quad$ Disponível em: $<$ https://www.researchgate.net/publication/268286804 DIAGNOSTICO DA PESCA NO LITORAL DO ESTADO DO RIO GRANDE DO SUL>. Acesso em: jan. 2017.

HELLEBRANDT, L. et al. Avaliação de políticas públicas aplicadas à pesca artesanal no Brasil. VI Encontro Nacional da ANPPAS. Belém. Pará, 2012.

JANN, W.; WEGRICH, K.The Theories of the policy cycle. In: FISHER, F.; MILLER, G. J.; SIDNEY, M. S. (Eds.). Handbook of policy analysis: theory, politics, and methods. CRC Press, 2007.

LIMA, L. L.; D’ACENZI, L. Implementação de Políticas Públicas: perspectivas Analíticas. Revista de Sociologia e Política, Curitiba, v. 21, n. 48, p. 101-110, dez. 2013.

LIPSKY, M. Street-Level bureaucracy: dilemmas of the individual in publicservices. RusselSagePublicationFoundation, 1980.

LIPSKY, M. Street-Level bureaucracy: dilemmas of the individual in Public Services. Sage, 2010.

LOTTA, G. S. Implementação de políticas públicas: o impacto dos fatores relacionais e organizacionais sobre a atuação dos Burocratas de Nível de Rua no Programa Saúde da Família. Tese (Doutorado em Ciência Política). São Paulo, 2010.

MENY Y.; THOENIG, J. C. Politiques publiques. Paris: PUB, Col, “Themis”, 1989

MULLER, P. Las políticas públicas. 4 ed. Paris: PUF, 2002.

O'BRIEN, K. J.; LI, L. Selective policy implementation in rural China. Comparative Politics, v. 31, n. 2, p. 167-186, 1999.

PRESSMAN, J. L.; WILDAWSKY, A. Implementation: how great expectations in Washington are dashed in Oakland, 3. ed. Berkeley: University of California Press, 1984.

RIO GRANDE DO SUL. Secretaria da Agricultura e Abastecimento. RS RURAL. Manual operativo. Porto Alegre. 2003.

RODRIGUES, P. D. Análise de políticas públicas: a influência dos StreetLevelBureaucrats (Burocratas de Nível de Rua) no processo de implementação da política habitacional do Estado de Minas Gerais. Tese (Mestrado) Viçosa, Minas Gerais. 2016.

SCHNEIDER, S.; CAZELLA, A. A.; MATTEI, L. Histórico, caracterização e dinâmica do Pronaf - Programa Nacional de Fortalecimento da Agricultura Familiar (19952003). In: SCHNEIDER, S.; SILVA, M. K.; MARQUES, P. E. M. (Org.). Políticas públicas e participação social no Brasil, 2. ed. Porto Alegre: Editora da UFRGS, 2009, p. 21-49. 
SILVA, P. L. B; MELO, M. A. B. O processo de implementação de políticas públicas no Brasil: características e determinantes da avaliação de programas e projetos. Campinas: UNICAMP, 2000.

SOUZA, C. Políticas públicas: uma revisão de literatura. Sociologias, Porto Alegre, v. 8, n. 16, p. 20-45, jul/dez. 2006.

SUBIRATS, J. et al. Análisis y gestión política públicas. Barcelona: Editorial Ariel, 2008. P. 33-47.

TRENTIN, I. C. L. O Pró-Rural 2000 como política pública de combate à pobreza rural no Rio Grande do Sul. 2001. Dissertação (Mestrado em Desenvolvimento Rural) - Curso de Pós-Graduação em Desenvolvimento Rural, Universidade Federal do Rio Grande do Sul, Porto Alegre.

WIKIPÉDIA. Tramandaí (2017). Disponível em: https://pt.wikipedia.org/wiki/Tramandaí. Acesso em: jul. 2017.

WU et al. Guia de políticas públicas: gerenciando processos. Brasília: ENAP, 2014. 